\title{
Changes of Structure and Physical-Mechanical Properties in Alloy Steels Thermochemically Treated by Plasma Nitriding
}

\author{
Florin $\mathrm{Ciofu}^{1, *}$, and Marius Bibu ${ }^{1}$ \\ ${ }^{1}$ Lucian Blaga University of Sibiu, Faculty of Engineering, Industrial Engineering and Management \\ Department, Romania
}

\begin{abstract}
Plasma nitriding is a method of surface modification using a glow discharge technology to introduce nitrogen into the surface of a metal, which subsequently diffuses into the material. The main advantages of plasma nitriding over conventional nitriding processes are: reduced cycle time, controlled growth of the surface layer, elimination of white layer, reduced distortion, no need of finishing, pore-free surfaces and mechanical masks instead of copper plating. The process is especially suitable for complex parts that are intensively solicited by wear, fatigue, contact pressure, shocks, possibly also to corrosion. It is applied in order to bring the metallic products in a state favourable from the point of view of structure, chemical composition and internal stress state. The paper presents an analysis of the structures and characteristics of a widely used structural steel - 39CrAl6. As a result of plasma nitriding, a surface layer with high wear and fatigue resistance was created on the surface of the material. Also, between the surface layer and the base material was interposed a hard substrate with high wear resistance having a bainitic / martensitic structure.
\end{abstract}

\section{Introduction}

In order to obtain high hardness on the surface of low carbon steels, thermochemical processes such as plasma carburizing or plasma nitriding can be used [1].

These processes add to the usual carburetion by offering appreciable repeatability and control, short heat treatment times and a low energy content [2].

Plasma carburizing and plasma nitriding do not cause deformations in the surface layer, this aspect leading to the reduction of the need for further processing by cutting. As the working temperatures are low in the case of plasma nitriding, the process has the smallest deformations in the surface, being indicated for increasing the hardness of molds, instruments and precision parts, etc. $[3,4]$.

The processes of austenitic gaseous heat treatments with carbonitriding are made in special furnaces using as working atmospheres mixtures of ammonia endothermic gases, with controlled nitriding with the help of infrared gas analyzers.

\footnotetext{
* Corresponding author: cristian.ciofu@ulbsibiu.ro
} 
The goal of this paper is to summarise the current status of austenitic carbonitriding and to illustrate the metallurgical principles involved, using, where possible, a single material the steel $39 \mathrm{CrAl} 6$ and a single processing temperature $\left(700^{\circ} \mathrm{C}\right)[3,4]$.

\section{Current status of austenitic carbonitriding}

Optimum treatment temperatures are in the range $675-775{ }^{\circ} \mathrm{C}$; at higher temperatures, thermal dissociation of ammonia is so great, that successful carbonitriding is not possible.

Processing times in excess of 1-2 hours do not appear to be justified. Optimum atmosphere conditions involve inlet gas mixtures containing between $65-70 \% \mathrm{NH}_{3}$ and $30-$ $35 \%$ endothermic gas, with the gas flow rates adjusted so as to exhibit a residual ammonia level of between $7-15 \%$ in the furnace [5].

The compound layer morphology is largely controlled by the processing temperature, but it is the level of non-dissociated ammonia that mainly dictates the compound layer thickness. Short treatment times generally result in a more compact and less porous compound layer and the optimum layer thickness is about $30 \mu \mathrm{m}$.

As with the ferritic carbonitriding treatment, the compound layer consists mainly of the c.p.h. $\varepsilon$ carbonitride phase, which is predominantly responsible for significant improvements in the tribological properties. The average nitrogen content of good-quality compound layers is about $6-7 \mathrm{wt} \%$ and carbon levels are usually maintained at less than $1 \%$. The microhardness of the compound layer is about $870 \mathrm{HV}$ at the surface region and decreases to about $600 \mathrm{HV}$ near the austenite boundary [5].

In order to obtain a corresponding surface hardness, it is necessary to change the austenitic zone under the composite layer into iron-nitrogen (carbon) bainite. The transformation temperatures vary depending on the base material, ranging from $250-300{ }^{\circ} \mathrm{C}$. The penetration depths of the transformed austenite reach up to $200 \mu \mathrm{m}$ and the hardness increases up to 900 $\mathrm{HV}$. The values of penetration depth and hardness can be improved if prior to carbonitriding, a precarburizing heat treatment is performed.

The resistance to various stresses (especially fatigue) of ordinary carbon steels increases by $60-100 \%$ after direct cooling from austenitic carbonitriding temperatures and is comparable (slightly lower) to ferritic carbonitriding. By applying an aging treatment on the austenitic area in the surface surface layer, a slight decrease in fatigue resistance is obtained, especially at high stress cycles [6].

The use of asthenic carbide in various industries has a frequent use, being successfully applied to both ordinary carbon steels and low-alloy steels. Common applications that require good wear resistance include: drive shaft, hand-brake ratchet, pump part, gears and pulleyes. Typical applications for enhanced fatigue life include crankshafts, steering pins, guide shafts and rocker arms.

In addition, applications are being found where the minimal degree of distortion associated with the treatment is of benefit and, accordingly, components such as bevel gears, which were previously carbonitrided at $870-950{ }^{\circ} \mathrm{C}$, are now subjected to the austenitic carbonitriding treatment [7].

\section{Principles of gaseous carbonitriding}

A gaseous carbonitriding process provides an atmosphere that facilitates the simultaneous addition of nitrogen and carbon to the surface layers of others based on iron, thus producing the epsilon phase. For a processing temperature of $700{ }^{\circ} \mathrm{C}$ for example, the relevant isothermal section of the Fe-C-N ternary system is represented in figure 1 [8], which 
illustrates the appropriate levels of nitrogen and carbon necessary to form the epsilon $(\varepsilon)$ carbonitride phase.

The mass transfer of these levels of nitrogen and carbon involves mainly two reactions, occurring simultaneously: a nitriding reaction and a carburising reaction. Generally, ammonia gas is used for the nitriding reaction, while endothermic gas is frequently employed for usage in the carburising reaction.

In the carburising part of the reaction endothermic gas of the following nominal composition is involved: $15-25 \% \mathrm{CO} ; 35-45 \% \mathrm{H}_{2} ; 35-40 \% \mathrm{~N}_{2} ; 0.05-0.15 \% \mathrm{CH}_{4} ; 0.3-$ $0.4 \% \mathrm{CO}_{2} ; 0.2 \% \mathrm{H}_{2} \mathrm{O}$.

The nitrogen in the active condition diffuses into the metal surface being treated, while the atomic hydrogen forms hydrogen gas. Ammonia gas also thermally dissociates at the processing temperature to give nitrogen and hydrogen gases.

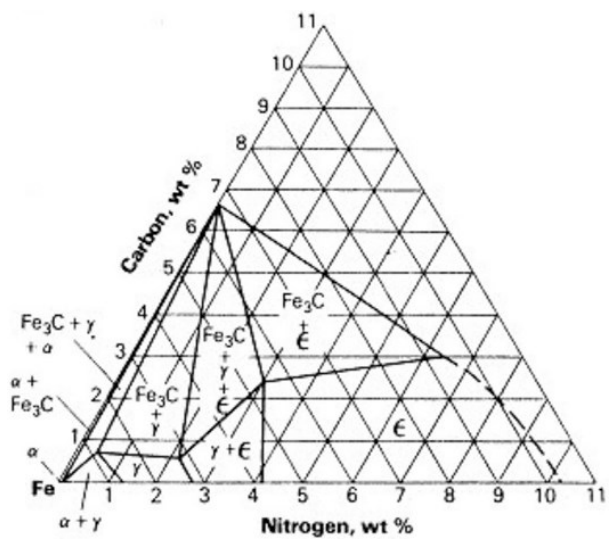

Fig. 1. Fe-C-N - Isothermal section phase diagram at $700{ }^{\circ} \mathrm{C}$.

However, since the solubility of nitrogen gas in the carbonitride phase and in austenite at one atmosphere pressure is extremely restricted $[8,9]$ the nitrogen potential of the nitrogen gas can be regarded as being negligible.

In industrial practice, by keeping the endothermic gas composition constant, the exhaust ammonia is taken as a reasonable measure of the nitrogen potential, but for thermodynamic studies this is not reliable and the above formula should be employed.

\section{Structures and properties resulting from austenitic carbonitriding}

Compound layer. As a practical example, a sample of 39CrAl6 steel subjected to an austenitic carbonitriding treatment at $700{ }^{\circ} \mathrm{C}$ with a $15 \%$ residual ammonia level in the exhaust gas atmosphere of a sealed-quench furnace, will be analysed. The chemical composition of steel 39 CrAl6 is: $0,32 \ldots 0,36 \% \mathrm{C} ; 0,55 \ldots 0,80 \% \mathrm{Mn} ; 0,030 \ldots 0,035 \% \mathrm{~S} ; 0,030 \ldots 0,035 \% \mathrm{P}$; $1,60 \ldots 1,80 \% \mathrm{Cr} ; 0,40 \ldots 0,50 \% \mathrm{Al} ; 0,030 \ldots 0,035 \% \mathrm{Si}$.

The appropriate microstructure after a 1 hour treatment is shown in figure 2. 


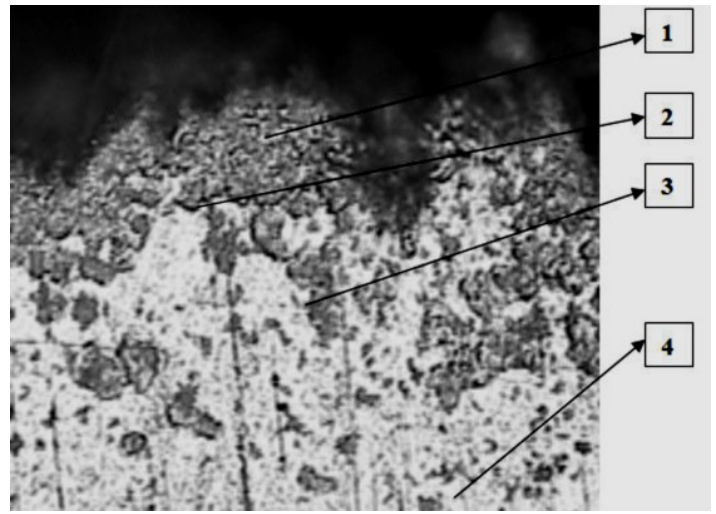

Fig. 2. Micrograph of $39 \mathrm{CrAl} 6$ carbonitrided for 1 hour at $700{ }^{\circ} \mathrm{C}$ in ammonia / endothermic gas with $15 \%$ residual $\mathrm{NH}_{3}$, and quenched in oil (x600): 1 - outer layer mechanically deposited on the surface when extracted from the crucible with molten aluminum, next to the feal phase $\mathrm{FeAl}_{3} ; 2$ - separation border (very thin), with the structure of phase of $\mathrm{FeAl}_{3} ; 3$ - diffusion layer having in the structure the phase $\mathrm{Fe}_{2} \mathrm{Al}_{5}$, with a thickness of up to $35 \mu \mathrm{m}$ ); 4 - sorbitic structure of the sample base material.

It is known, that these conditions provide a sufficiently high nitriding potential to produce the desired epsilon phase at the outermost surface and a sub-surface austenitic zone [10].

Decomposition of the austenite zone. The morphology and kinetics of the decomposition of hypereutectoid iron-nitrogen austenite to nitrogen bainite have been studied extensively [4]. The net effect of this fine-scale bainite formation is shown on an optical micrographic scale in figure 3; as a result there is a very significant increase in the matrix hardness as is illustrated in figure 4.

Accordingly, when the nitrocarburised $39 \mathrm{CrAl} 6$ steel is aged at a suitable temperature, the zone beneath the epsilon compound layer undergoes the reaction described above, with a subsequent increase in hardness of the prior austenite region. This situation is illustrated in figure 5 .



Fig. 3. Micrograph of $\mathrm{Fe}-2,6 \mathrm{wt} \% \mathrm{~N}$ fully transformed at $310{ }^{\circ} \mathrm{C}(\mathrm{x} 600)$. 


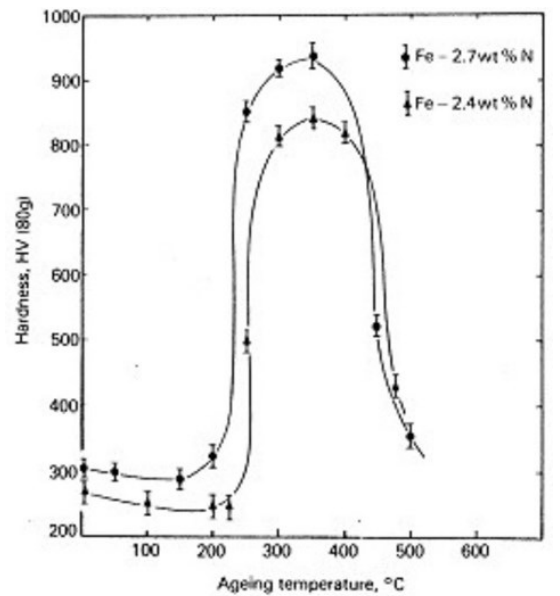

Fig. 4. The hardness of austenitic iron-nitrogen alloys after ageing for 30 minutes at various temperatures.

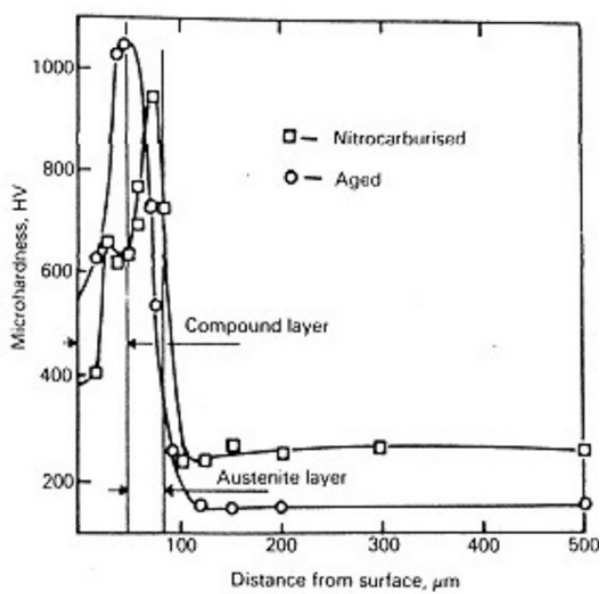

Fig. 5. Microhardness profiles for austenitic nitrocarburised $39 \mathrm{CrAl} 6$ before and after ageing at $250{ }^{\circ} \mathrm{C}$ for 2 hours (nitrocarburised for 1 hour at $700{ }^{\circ} \mathrm{C}$ in ammonia / endothermic gas with $15 \%$ residual $\mathrm{NH}_{3}$, and oil quenched).

Wear and fatigue resistance enhancement. A great advantage of carbonitriding is the significant increase in wear resistance attributed to the formation of the compound layer. This is shown in figure 6, [9] in the form of results of a pin-on-disc wear test. It can also be seen that the hardening of the substrate, as a result of the presence of a bainitic/martensitic structure, significantly enhances the wear resistance.

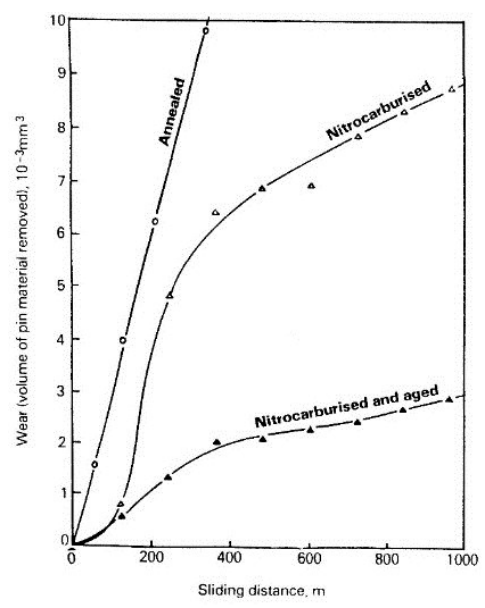

Fig. 6. Wear rates of $39 \mathrm{CrAl6}$ in the annealed, austenitic-carbonitrided, and austeniticcarbonitrided-and-aged-conditions carbonitriding at $700^{\circ} \mathrm{C}$ for 1 hour in ammonia/ endothermic gas with $15 \%$ residual ammonia, oil quenched, ageing at $250{ }^{\circ} \mathrm{C}$ for 2 hours.

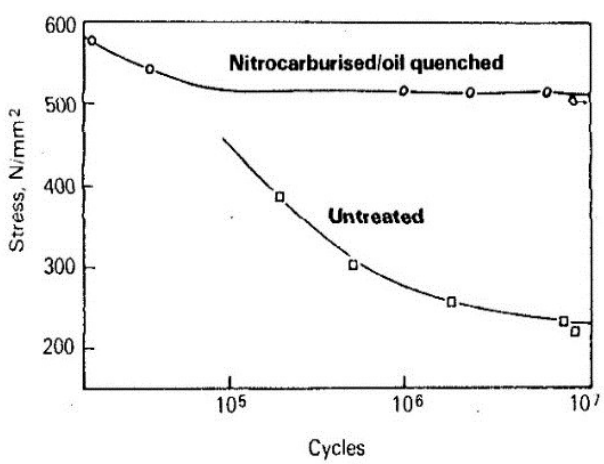

Fig. 7. Wohler fatigue curves of untreated $39 \mathrm{CrAl} 6$ and $39 \mathrm{CrAl} 6$ carbonitrided at $700{ }^{\circ} \mathrm{C}$ for 1 hour in ammonia / endothermic gas with $9,5 \%$ residual $\mathrm{NH}_{3}$ and oil quenched.

A further important benefit, which arises from the nature of the diffusion zone, is the improvement in fatigue resistance conferred by carbonitriding (figure 7). It has been reported 
that the fatigue strength of a low-carbon steel is decreased somewhat after ageing, and this is in agreement with other observations [9].

\section{Conclusions}

Applying the plasma carbonitriding process, four successive areas can be observed in the structure of the samples.

A mechanically adherent layer was deposited on the surface of the sample both during immersion in meltin bath and during extraction from the melt. The separation surface has an irregular shape in all samples subjected to carbonitriding, this aspect being caused by the interdiffusion process that occurs during the treatment. The variable thickness of this first layer was the result of an inconsistent extraction speed from the melting bath and the nitriding temperature. When examining the microstructure, it was observed that this outer layer is not only made of aluminum. Among the grains of aluminum not attacked by nital, an intercrystalline metallographic constituent was highlighted, very strongly attacked $\left(\mathrm{FeAl}_{3}\right)$.

A very finely demarcated and strongly attacked nital separation boundary was also observed between the surface layer and the diffusion layer. A third layer was formed under the diffusion layer, containing a lot of aluminum and slightly attacked with nital. Based on comparisons made with determinations analyzed in other specialized papers, we concluded that this layer consists of the $\mathrm{Fe}_{2} \mathrm{Al}_{5}$ phase.

The boundary of separation between this layer and the base material also showed an irregular shape (we assimilated it with a dendritic appearance).

The variation of the diffusion layer thickness (from 20 to $35 \mu \mathrm{m}$ ) was influencemd by the melting bath immersion duration and the aluminization temperature. In the carbonitrided samples, the thickness of the diffusion layer increased to $45 \mu \mathrm{m}$.

\section{References}

1. M.A. Fontes, R.G. Pereira, F.A.P. Fernandes, L.C. Casteletti, P.A. de Paula Nascente, J. Mater. Res. Technol. 3, 210 (2014)

2. F.M. Borodich, In Advances in Applied Mechanics; Bordas, S.P.A., Ed.; Elsevier: New York, NY, USA, 47, 225 (2014)

3. M.F. Yan, B.F. Chen, B. Li, Appl. Surf. Sci. 455, 1 (2018)

4. S. Zhang, L. Wang, Q. Wang, Surf. Coat. Technol., 214, 153 (2013)

5. A.P. Tschiptschin, L.B.Varela, C.E.Pinedo, X.Y.Li, H. Dong, Surf. Coat. Technol., 327, $83(2017)$

6. D. Dobrotă, Metalurgija, No.2, 53, (2014)

7. Y.X. Wang, S. Zhang, J. Lee, W.S.Lew, D. Sun, Surf. Coat. Technol., 231, 346 (2013)

8. H.J.Brinkman, F. Zupanic, J. Duszczyk, L. Katgerman, Journal of Materials Research, 15/12, 627, (2000)

9. M. Bibu - Researches regarding the working out of local protection technologies at plasma thermochemical treatments (in Romanian), Ph.D. Thesis, Lucian Blaga University of Sibiu, (1998)

10. F. Ciofu - WSEAS Conference, 6th International Conference on Manufacturing Engineering, Quality and Production Systems (MEQAPS '13) Braşov, (2013) 